\title{
Highly Skilled or Highly Wanted Migrants? Conceptualizations, Policy Designs and Implementations of High-skilled Migration Policies
}

\author{
Metka Hercog, Laure Sandoz
}

\section{Introduction}

Although research on skilled migration has proliferated in the past (Boucher \& Cerna, 2014; Fei, Graeme, \& Massimiliano, 2014), it is notable that the issue of skill conceptualisation and the use of terms in practice is largely glanced over or relegated to a footnote. Devoting a special issue to the problematisation of migrant categories in selective migration regimes attempts to fill this gap. By proposing a critical perspective on highly skilled migration, the special issue shifts the focus from an approach that takes the category of "highly skilled migrant" for granted to an approach that regards contexts as crucial for structuring migrants' characteristics, trajectories and experience, and for informing our perception of them as high-skilled or low-skilled, wanted or unwanted, welcome or unwelcome.

This special issue offers an opportunity to delve into the construction of migrant categories through policy design and policy implementation. It proposes to widen the focus beyond immigration authorities in order to include actors that are in one or another way involved in the process of selecting, supporting or employing highly skilled workers and therefore also contributing to their definition. The aim of the special issue is to bring to the surface the indistinct objectives of immigration policies, and to analyse the interplay between policies, discourses and practices. More precisely, we discuss the argument that the definition of highly skilled migrants depends more on how potential migrants are viewed by interest groups than on migrants' characteristics.

\section{What is the gap we want to fill?}

The proliferation of selective migration policies has sparked new interest in academic research on highly skilled migration (Boeri et al. 2012; Boucher and Cerna 2014; Chaloff and Lemaitre 2009; Favell, Feldblum, and Smith 2006; Kõu et al. 2015; Mau et al. 2015). Several studies observe the importance of policy changes on the structure of migration flows throughout time and assess the link between the increasing skill-focus of immigration policies and growing flows of skilled migrants to leading industrialized countries (Mayda 2010; Ortega and Peri 2013; Palmer and Pytlikova 2015). Another strand of literature focuses on the reasons behind policy changes, listing processes of technological advancement, population ageing and globalization of production as the main causes for kindling international competition for talent (Kapur \& McHale, 2005; Koser \& Salt, 1998). Yet, while several authors dealing with comparative methodologies analyse differences and similarities between immigration regimes intended to attract highly skilled workers (Cerna 2013; Hercog and Wiesbrock 2016; Laudel 2005), questions of who and what constitutes skilled migration are only starting to emerge in the scientific literature (Boucher and Cerna 2014; Favell, Feldblum, and Smith 2006; Parsons et al. 2014; Tannock 2011). Whom are these regimes aimed at? Despite the fact that the term "highly skilled" gives an indication that people included in this stream of migration are highly educated, this is not necessarily the case. As the article by Kulu, Schans and Smit in this special issue shows many other factors come into play. In some cases, for example in the Netherlands, 
education does not even play a defining role for someone to be eligible for a "knowledge migrant" scheme. Given that immigration policies differ considerably among each other, it is obvious that there is no common agreement on the definition of 'high skills'.

\section{Content of the Special Issue}

The seven articles that compose this special issue enable different forms of comparison of how highly skilled migrants are perceived and defined by various actors in different places and times. While several authors take a policy perspective to analyse the legal and administrative practices that contribute to the selection of "wanted" migrants in different countries (Hercog \& Sandoz; Kulu, Schans \& Smit; Andriescu), others take a more sociological perspective to reflect on the impact of social contexts in shaping career paths and experiences of skilled migrants (Tissot; de Sousa Ribeiro; Sontag). One author also offers a historical perspective by comparing the way a specific group of skilled migrants has been perceived differently through time (Peppler). All the articles combine at least two different methods (policy analysis, survey analysis, participant observation and/or interview analysis), which enables them to highlight discrepancies between norms, discourses and practices. They show that official policy aims are rarely met in practice, and that categorisation processes rely on complex power relations between social actors with competing objectives. They also enable the comparison between situations structured by different policies, institutions and social dynamics, thus highlighting the constructed nature of the category of highly skilled migrants, as well as the economic, social, and political issues that frame it.

The three first articles of the special issue highlight the importance of national qualification recognition processes. They show how the policies that regulate diploma recognition for different professions within specific countries contribute to defining the "wanted" migrants who get privileged access to the labour market of specific countries, while excluding those with less valued qualifications. The attention to skill recognition policies adds another layer of complexity to the issue of immigrant selection by showing that these policies fulfil a similar role as admission policies.

The contribution by Monica Andriescu highlights the context-dependent dimension of skill valuation by showing the relationship between local labour shortages and skill recognition policies. Her research reveals that the immigrants with qualifications that belong to an official labour shortage list encounter less difficulties to make their skills officially recognised in Germany than the immigrants with qualifications that are less sought after locally. Moreover, she argues that skill recognition policies belong to the realm of migration selection because they contribute to defining more or less wanted categories of immigrants. By focusing on the case of highly qualified Romanian immigrants in Germany, she shows that even in a context of free movement of persons, recognition policies defined by national and local governments enable the selection of immigrants according to economic needs. In this way, some immigrants easily access jobs that match their qualification level, while others encounter more obstacles and often end up accepting professional positions that do not correspond to their education. The relationship between qualifications, policies and local labour market dynamics is thus central for defining the value of immigrants in this context.

Similarly, Joana Sousa Ribeiro argues that being recognised as highly skilled not only depends on one's qualifications but also relies on the interaction between policies, institutional practices and individual trajectories. By focusing on illegalised doctors from non-EU countries in Portugal who are prevented from working in their field of expertise due to their illegal residence status and 
unrecognised diploma, she shows how a combination of top-down and bottom-up initiative has enabled some of them to enter special recognition programmes and eventually obtain a right to work as doctors in Portugal. In this way, she sets a distinction between the two status of "ascribed qualified migrant" and "achieved skilled migrant", arguing that only the second one gives access to full participation in society. The main strength of her contribution is to highlight the interaction between different analytical levels (macro, meso and micro) in the social construction of "achieved skilled migrants".

Finally, Lisa Peppler's contribution highlights the fragility of privileges and the impermanence of categories. She offers a historical perspective on the changing valuation process of Turkish medical doctors in Germany since the 1960s, showing how, after having been welcomed with open arms at a time of shortage, physicians from Turkey have gradually been excluded from the German labour market and have needed to develop new strategies to practice in this country. In this exclusionary context, they could use their ethnicity as a resource, thus becoming Turkish physicians specialising on Turkish patients instead of simply "physicians", as had been the case before. However, the development of free movement of persons within the EU further restricted access to Germany for Turkish nationals, whereas labour shortages created new preferences for physicians from Eastern Europe rather than from Turkey. In this context, the interaction between immigration policies and the policies regulating the medical profession in Germany created changing dynamics of inclusion and exclusion over time, which gradually limited the possibilities for physicians from Turkey to practice medicine in Germany.

The two next articles of the special issue focus on the relationship between policy definitions and policy implementation. They show that official policy objectives are not always translated into practice and that definitions of "highly skilled migration" involve negotiations between conflicting objectives at different levels of policy development and implementation processes.

Our contribution to this special issue focuses on the way cantonal authorities in charge of admitting third-country workers in Switzerland define the desirable immigrants who can get access to the national territory and labour market. We show that beyond the official objective of selecting economically valuable immigrants, the Swiss admission policy serves as a symbolic tool to communicate power and control over immigration. In this sense, authorities take into account both economic and non-economic objectives when selecting immigrants in an attempt to reconcile conflicting economic, social and political priorities. It results in an unclear, context-dependent definition of "highly skilled migrants" that enables the authorities to select candidates to immigration as strictly as possible based on their immediate priorities rather than based on the individual characteristics of the immigrants.

In a similar vein, the article by Isik Kulu-Glasgow, Djamila Schans and Monika Smit highlights the mismatch between the highly skilled migrants that the Dutch government tries to attract through targeted policies and the people who actually use these policy schemes. Using data from a web survey with participants in one of the most recent policy instruments in the Netherlands, the Orientation Year for Highly Educated Migrants Scheme, they show that despite the goal of the Dutch government to attract non-EU young 'top-talents', the migrants who obtain permits through this policy scheme are in majority people with personal ties in the Netherlands and the intention to come anyway, with or without the Orientation Year. The authors thus reveal the importance of social capital over economic motivations in the case of this scheme. Moreover, they invite to a better consideration by researchers of the discrepancy between official definitions of "wanted" 
migrants in policy documents and the actual characteristics of the individuals that these policies affect in practice.

The last two articles of the special issue address in more details the "human face of global mobility" (Favell, Feldblum, and Smith 2006). They shed light on two very different forms of highly skilled migration: the situation of highly qualified refugees trying to access higher education and the situation of working professionals and their families supported by "migration intermediaries" (Groutsis et al. 2015). Each case presents some of the difficulties associated with these different forms of migration, as well as the strategies that individuals mobilise to overcome them. Moreover, they nicely conclude our discussion on the conceptualisation of skills by showing how two groups of highly skilled migrants end up being categorised in very different ways because of the interaction between their specific biography and the institutional context in which they are embedded.

Katrin Sontag's contribution focuses on a subject rarely associated with the field of high-skilled migration: the case of refugees who try to complete their higher education. She highlights the many obstacles that these people encounter when trying to make their skills recognised after fleeing their country and critically addresses the issue of the transferability of skills. She argues that the opportunities that different social spaces offer vary radically depending not only on migrants' skills and education, but also on the channel through which they enter a country. It is thus of crucial importance to analyse the effect of policies and administrative practices on individual situations. Moreover, her contribution encourages researchers to be careful not to reproduce without questioning the political categories that rely on assumptions about the value of different groups of immigrants.

Lastly, the contribution of Florian Tissot focuses on the "migration intermediaries" who encourage the mobility of certain migrants. By describing the different types of services that such intermediaries offer to support the relocation of international employees and their families in Switzerland, the article shows that migration is a business in which some actors invest considerable resources to attract the workers that they perceive as most valuable. It also reveals some of the mechanisms through which intermediaries construct migration as a smooth and unproblematic process for some people, securing in this way access to a mobile, flexible and international workforce for the employers. At the same time, the article highlights the limits of such constructions by presenting some of the difficulties that these mobile people experience when relocating to a new place.

Overall, the seven articles highlight the power that states continue to have to categorise individuals and to define their rights and obligations within given territories. Although highly skilled migrants are often viewed as higher-end, more sought after, and freer of constraints than other groups of migrants, this special issue shows that even the most qualified migrants can be affected by restrictive policies. Moreover, the articles convincingly demonstrate that both the value and potentiality of skills are framed by economic, social, and political contexts.

At a time when researchers and policy-makers increasingly see migrants from the perspective of their potential benefits for the host societies, it is important to take a step back and reflect on the role of skills and knowledge in determining a migrant's ability to move, stay and perform in places. Moreover, we believe that researchers need to critically analyse the impact of changing governments' priorities and ideologies on these processes. As Adrian Favell $(2008,271)$ rightly puts it: 
Instead of telling a story about how foreign objects (migrants) fit into or challenge the given (nation-state) narrative and institutional structures by which we recognize the world, we might instead look at how the very process by which collectivities manage movers by naming and counting them, and thereby distinguishing them from nonmovers or residents, is the fundamental way in which the territorial nation-state society constitutes itself in the first place.

This is necessary if we want research to remain an independent field of knowledge production instead of a tool in the service of states that legitimises their restrictive migration policies.

Beyond immigration authorities, the seven articles also highlight the role of other actors that are in one or another way involved in the process of selecting, supporting or employing highly skilled workers, and therefore contributing to the definition of migrant categories. Accelerated international migration flows require an updated examination of relevant stakeholders at the national, international and transnational level. This is important if we want to reach a better understanding of the situated mechanisms that underlie the construction of "highly skilled migrants" as a category framed by needs and interests in specific place and time.

\section{Conclusion}

The research presented in this special issue offers an interdisciplinary perspective on the construction of migrant categories by analyzing the role of policy design and policy implementation in defining "highly skilled migrants". The seven chapters enable different forms of comparison of how highly skilled migrants are perceived and defined by various actors in different places and times. The variety of approaches and topics enables the creation of a collection in which each article complements the others towards a common goal: A better understanding of the mechanisms underlying the construction of "highly skilled migrants" as a category.

The special issue shows that immigration policy is never simply merit based or simply about meeting labour market needs. Future research should, thus, consider the limits of declared policy objectives and be careful about reproducing political categories, even when these categories are meant to have a positive value. Clearly, the use of categories such as "highly skilled migrants" bestows privileges to some people and excludes others. Expanding our observations to groups which are not benefiting from easy admission and associated rights on the labour market is pertinent to show that migrants' individual characteristics alone do not secure a privileged position in society. Cases such as medical doctors whose qualifications are not recognized, highly-educated refugees or accompanying spouses show us how people become categorised in very different ways because of the institutional channels through which they enter a country (Sandoz, 2018). Instead of assuming a certain type of people fitting with the category of the highly skilled, we stress the need to consider the filters through which people have to pass. Migration governance needs to be approached holistically, encompassing not only admission and integration policies, but also skill recognition policies, labour market policies and higher education programmes. Altogether, the interplay between policies, discourses and practices influences the composition of immigration flows and guides potential skilled migrants to particular privileges in society. As the historical approach shows us, privileges may also be taken away. Hence, the category of highly skilled migrants is constantly negotiated and contested and can only be used as a category of practice. 


\section{Acknowledgement}

The development of this special issue was supported by the National Centre of Competence in Research (NCCR) - on the move, which is funded by the Swiss National Science Foundation.

\section{References}

Boeri, Tito, Brücker, Herbert, Docquier, Frederic, and Hillel Rapaport, eds. 2012. Brain Drain and Brain Gain: The Global Competition to Attract High-Skilled Migrants. Oxford: Oxford University Press.

Boucher, Anna, and Lucie Cerna. 2014. "Current Policy Trends in Skilled Migration Policy." International Migration 52(3): 21-25.

Cerna, Lucie. 2013. "The EU Blue Card: Preferences, Policies and Negotiations Between Member States". Migration Studies, 2(1): 73-96. doi:10.1093/migration/mnt010

Chaloff, Jonathan and George Lemaitre. 2009. Managing Highly-Skilled Labour Migration: A Comparative Analysis of Migration Policies and Challenges in OECD Countries. OECD Social, Employment and Migration Working Papers, 79.

Favell, Adrian, Feldblum, Miriam, and Michael Peter Smith. 2006. The Human Face of Global Mobility: A Research Agenda. In The Human Face of Global Mobility: International Highly Skilled Migration in Europe, North America and the Asia-Pacific, edited by Michael Peter Smith and Adrian Favell. 1-29. New Brunswick, NJ: Transaction Publishers.

Favell, Adrian. 2008. Rebooting Migration Theory. Interdisciplinarity, Globality, and Postdisciplinarity in Migration Studies. In Migration Theory. Talking across Disciplines, edited by Caroline B. Brettell and James F. Hollifield, 259-278. New York: Routledge.

Guo, Fei, Hugo, Graeme and Massimiliano Tani, eds. "The Globally Mobile Skilled Labour Force: Policy Challenges and Economic Opportunities." Special Issue, International Migration 52 (2) (2014).

Groutsis, D., Van den Broek, D. and W. Harvey. 2015. "Transformations in Network Governance: The Case of Migration Intermediaries." Journal of Ethnic and Migration Studies 41(10): 1558-1576.

Hercog, Metka and Anja Wiesbrock. 2016. Highly Skilled Migration in the EU and the US: The Legal Framework. In Adjusting to a World in Motion: Trends in Global Migration and Migration Policy, edited by Douglas Besharov and Mark Hugo Lopez, 232-264. Boston: Oxford University Press.

Kapur, Devesh and John McHale. 2005. Give Us Your Best and Brightest: The Global Hunt for Talent and Its Impact on the Developing World. Washington, D.C.: Center for Global Development

Koser, Khalid and John Salt. 1997. "The Geography of Highly Skilled International Migration". International Journal of Population Geography, 3(4), 285-303.

Kõu, Anu, van Wissen, Leo, van Dijk, Jouke and Ajay Bailey. 2015. “A Life Course Approach to High-skilled 
Migration: Lived Experiences of Indians in the Netherlands". Journal of Ethnic and Migration Studies, 41(10): 1644-1663. doi: 10.1080/1369183X.2015.1019843

Laudel, Grit. 2005. "Migration Currents Among the Scientific Elite”. Minerva, 43 (4): 377-395.

Mau, Steffen, Gülzau, Fabian, Laube, Lena and Natascha Zaun. 2015. “The Global Mobility Divide: How Visa Policies Have Evolved over Time”. Journal of Ethnic and Migration Studies, 41(8): 1192-1213.

Mayda, Anna Maria. 2010. "International Migration: A panel data analysis of the determinants of bilateral flows". Journal of Population Economics, 23(4): 1249-1274.

Ortega, Francesco and Giovanni Peri. 2013. "The Effect of Income and Immigration Policies on International Migration". Migration Studies, 1(1): 47-74.

Palmer, John and Mariola Pytlikova. 2015. "Labor Market Laws and Intra-European Migration: The Role of the State in Shaping Destination Choices." European Journal of Population, 31(2): 127-153.

Parsons, Christopher, Rojon, Sebastien, Samanani, Farhan and Lena Wettach. 2014. "Conceptualising International High-Skilled Migration". The International Migration Institute (IMI) Working Paper Series, no. 104, Nov. 2014. Retrieved from http://www.imi.ox.ac.uk/pdfs/wp/wp-104-14.pdf

Sandoz, L. 2018. Understanding access to the labour market through migration channels. Journal of Ethnic and Migration Studies. DOI: 10.1080/1369183X.2018.1502657

Tannock, Stuart. 2011. "Points of Prejudice: Education-Based Discrimination in Canada's Immigration System”. Antipode, 43(4): 1330-1356. 